\title{
Implications of taxonomic bias for human-carnivore conflict mitigation
}

\author{
Clatre F. Hoffmann and Robert A. Montgomery
}

\begin{abstract}
Carnivore population declines are a time-sensitive global challenge in which mitigating decreasing populations requires alignment of applied practice and research priorities. However, large carnivore conservation is hindered by gaps among research, conservation practice and policy formation. One potential driver of this research-implementation gap is research bias towards charismatic species. Using depredation of livestock by large carnivores in sub-Saharan Africa as a case study, we examined whether taxonomic bias could be detected and explored the potential effects of such a bias on the research-implementation gap. Via a literature review, we compared the central large carnivore species in research to the species identified as the primary livestock depredator. We detected a substantial misalignment between these factors for two species. Spotted hyaenas Crocuta crocuta were the most common depredator of livestock (58.5\% of studies), but were described as a central species among only $20.7 \%$ of the studies. In comparison, African lions Panthera leo were the most common central species ( $45 \%$ of studies) but were the primary depredator in just $24.4 \%$ of studies. Such patterns suggest that taxonomic bias is prevalent within this research. Although spotted hyaenas may depredate livestock most often, their low charisma in comparison to sympatric species such as the African lion and leopard Panthera pardus may be limiting research-informed conservation efforts for them. Efforts to mitigate human-carnivore conflict designed for one species may not be applicable to another co-occurring species, and thus, taxonomic bias could undermine the efficacy of interventions built to reduce livestock depredation by carnivores.
\end{abstract}

Keywords Charisma, Crocuta crocuta, human-carnivore conflict, livestock depredation, research-implementation gap, sub-Saharan Africa, taxonomic bias

Claire F. Hoffmann (Corresponding author, (D) orcid.org/0000-0001-73124459, clairefhoffmann@gmail.com) Research on the Ecology of Carnivores and their Prey Laboratory, Department of Fisheries and Wildlife, Room 13, Natural Resources Building, Michigan State University, 480 Wilson Road, East Lansing, Michigan 48824, USA

Robert A. Montgomery Wildlife Conservation Research Unit, Department of Zoology, University of Oxford, Tubney, Oxon, UK

Received 16 September 2020. Revision requested 26 January 2021.

Accepted 12 April 2021. First published online 9 February 2022.
Supplementary material for this article is available at doi.org/10.1017/So030605321000582

\section{Introduction}

T arge carnivores are of conservation concern globally. 1 More than $75 \%$ of the remaining large carnivore species have declining population trajectories (Chapron et al., 2014; Ripple et al., 2014; Eklund et al., 2017). Furthermore, the majority of these species are categorized as threatened (Vulnerable, Endangered or Critically Endangered) on the IUCN Red List, with some experiencing $>90 \%$ range contraction over the last century (Ripple et al., 2016; Wolf \& Ripple, 2017). Widespread concerns relating to carnivore conservation are reflected in the literature; publication of peer-reviewed research has increased exponentially in the last 3 decades (Krafte Holland et al., 2018; Montgomery et al., 2018a,b; Lozano et al., 2019). This literature has identified a number of drivers of carnivore population declines, including habitat loss, prey depletion, disease and climate change (Inskip \& Zimmermann, 2009; Estes et al., 2011; Ripple et al., 2016; Wolf \& Ripple, 2017). However, retaliation for livestock depredation is consistently cited as one of the primary threats to carnivore population persistence (Inskip \& Zimmermann, 2009; Tumenta et al., 2013; Ripple et al., 2014; Krafte Holland et al., 2018; van Eeden et al., 2018a,b).

As funds for conservation work are limited, each conservation project needs to use resources efficiently, to maximize positive on-the-ground impacts (Balmford et al., 2003; Brambilla et al., 2013; Eklund et al., 2017). To do so, research must be interpretable by conservation practitioners and policy makers (Balmford et al., 2003; Knight et al., 2008; Bennett et al., 2015; Ripple et al., 2016). However, even after extensive calls for improvement, significant gaps between research and conservation implementation remain (Knight et al., 2008; Eklund et al., 2017; Krafte Holland et al., 2018; Montgomery et al., 2018a,b; Gray et al., 2019). Factors contributing to this research-implementation gap include limited interdisciplinarity within research teams, scale discordance, and limited actionability of research (Montgomery et al., 2018a,b; Gray et al., 2019). Another factor that may be influential in this context is taxonomic bias.

Taxonomic bias is prevalent throughout conservation research, and describes a tendency for research effort, funding, and public interest to focus on a small subset of species 
(Clark \& May, 2002; Lawler et al., 2006; Stroud et al., 2014; Di Marco et al., 2017; Donaldson et al., 2017; Troudet et al., 2017; Tensen, 2018). This bias is primarily driven by human social factors, including perceptions of species charisma, and the value of those species for society and as subjects of conservation funding (Bonnet et al., 2002; Donaldson et al., 2017; Rosenthal et al., 2017). This uneven distribution of research and funding among taxa can result in mismatches between research effort, the resulting knowledge base, and conservation needs (Bonnet et al., 2002; Linklater, 2003; Fazey et al., 2005; Lawler et al., 2006; Wilson et al., 2007; Hortal et al., 2015; Rosenthal et al., 2017). These biases are not only influential between taxonomic orders but also within them, and may have important consequences for the researchimplementation gap (Anon., 2007; Knight et al., 2008; Martín-López et al., 2009; Trimble \& van Aarde, 2012; Fleming \& Bateman, 2016). To mitigate these effects, regular assessments of taxonomic bias have been recommended (Lawler et al., 2006; Wilson et al., 2007; Di Marco et al., 2017). Although previous studies have explored taxonomic bias in other conservation fields, its effect on the researchimplementation gap has not previously been evaluated for the literature on the depredation of livestock by carnivores.

Here, we used livestock depredation by large carnivores in sub-Saharan Africa as a case study to assess whether taxonomic bias is evident in human-carnivore conflict research. We conducted a literature review and compared the central carnivore species of each study to those identified as being most responsible for livestock depredation. We then examined the ways in which misalignment among these factors could contribute to the research-implementation gap affecting human-carnivore conflict mitigation. We explore the role of species charisma in catalysing research effort and conservation funding, and discuss the implications of our study for interventions and policies that could promote human-carnivore coexistence.

\section{Methods}

The term human-carnivore conflict obscures the nuanced experiences inherent in interactions between people and carnivores (Dickman, 2010; Redpath et al., 2013; Redpath, 2015; Krafte Holland et al., 2018; Lozano et al., 2019). We acknowledge that in assessing livestock depredation by carnivores, our study does not allow a broader perspective on both positive and negative human-wildlife interactions. However, we focused our review on livestock depredation as it is often a primary driver of agonistic interactions between people and carnivores and thus is a threat to carnivore conservation (Inskip \& Zimmermann, 2009; Tumenta et al., 2013; Ripple et al., 2014). Furthermore, minimizing depredation is a common aim of efforts to improve human-carnivore coexistence (Krafte Holland et al., 2018; van Eeden et al., 2018a,b). We chose to highlight sub-Saharan Africa because it is a hotspot for livestock depredation by carnivores, and carnivore biodiversity (Ripple et al., 2014; Krafte Holland et al., 2018; Lozano et al., 2019).

We completed our review in June 2019, using four bibliographic databases: Web of Science Core Collection (Clarivate Analytics, Philadelphia, USA), Scopus (Elsevier, Amsterdam, The Netherlands), Wildlife and Ecology Studies Worldwide (EBSCO, Baltimore, USA) and Google Scholar (Google, Mountain View, USA). We conducted our review in English, as it is the predominant publication language for studies on livestock depredation by carnivores (Krafte Holland et al., 2018; van Eeden et al., 2018a,b). Using an iterative search process, we searched each database a total of three times. We first included the term 'human carnivore livestock', adding 'conflict' in the secondary search and 'depredation' in the tertiary. As the database used by Google Scholar is not limited to scientific publications, we used additional specificity in our search on that platform. Specifically, we started our search of Google Scholar using 'human carnivore conflict' as a bound phrase (i.e. with the search term enclosed in quotations, so that the search results only include the exact phrase) and added 'livestock' and 'depredation' in the secondary and tertiary searches, respectively. We excluded any studies that were not published in a peer-reviewed journal, those that were outside the geographical extent of sub-Saharan Africa, and those that were not directly relevant to our assessment (e.g. carnivore predation of wild prey, carnivore attacks on people, or human attitudes towards conservation actions). For each study we recorded: (1) the location of the field site, (2) the central (i.e. focal) carnivore species, and (3) the carnivore species responsible for the majority of livestock depredation. For studies that did not provide exact geographical coordinates, we approximated the field site location based on site maps and study area descriptions. We selected the centroid for those that included multiple field sites.

\section{Central species}

We identified the central carnivore species of each study using lexical analysis with MAXQDA Analytics Pro 20.0.8 (Kuckartz \& Radiker, 2019). We conducted lexical searches among all studies to record the number of times that depredating carnivore species were mentioned. Our search terms included 'African lion' Panthera leo, 'spotted hyaena' Crocuta crocuta, 'African wild dog' Lycaon pictus, 'leopard' Panthera pardus, 'Ethiopian wolf Canis simensis, 'cheetah' Acinonyx jubatus, 'jackal' Canis mesomelas, 'brown hyaena' Parahyaena brunnea, 'African wolf Canis lupaster, 'caracal' Caracal caracal and 'striped hyaena' Hyaena hyaena. We used only the common name of each species as a search term, included the alternate spelling of hyaena (i.e. hyena) for all three hyaena species, and specified each search term to be a character string instead of a bound phrase. 
We also included words from the lemma list without case sensitivity. With these search settings, MAXQDA returned a hit for any combination of the search terms and any word forms (Kuckartz \& Radiker, 2019). For example, 'lion' returned a hit for the exact match, along with 'Lion' and 'lions'. For each study, we recorded the number of hits for each carnivore species within all sections of the document, excluding the references and running title. We converted the number of hits by carnivore species into a per cent of the total hits in the study. We considered a carnivore species to be central if the number of hits were $\geq 25 \%$ of the total hits for that study. Thus, it was possible for a study to have multiple central species. We classified a study as having no central species if none had $\geq 25 \%$ of the total hits.

Lexical analysis is an established tool for assessing textbased media, as high frequency terms are representative of content themes and biases (Wodak \& Meyer, 2008; Bednarek \& Caple, 2014). Lexical analyses are replicable, quantifiable and unbiased, and thus are valuable for studies of taxonomic bias (dos Santos et al., 2020). However, as the application of this method is emergent in conservation, we used a secondary document analysis to verify our results, identifying the central species based upon references to carnivore species throughout the document. For example, we classified a study to be centred around the spotted hyaena if that was the primary species around which the introduction, methods and results were framed. We performed the document analysis separate from the lexical analysis, to minimize the risk of implicit coding bias from the results of the lexical analysis.

\section{Measures of livestock depredation}

Next, we determined the carnivore species responsible for the majority of livestock depredation in each study. We used the two most prevalent methods for measuring livestock depredation (Krafte Holland et al., 2018): quantitative measures of livestock depredated by carnivores (e.g. the number of livestock killed), and perceptions of depredation risk among livestock owners (e.g. the proportion of respondents who considered a carnivore species to be the greatest threat to their livestock; Marker et al., 2003; Kissui, 2008; Miller et al., 2016a,b). We identified the carnivore species with the greatest contribution to these two conflict measures, depending on which was reported. Thus, our final database consisted of the geographical location, the central carnivore species and primary depredator for each study. We then mapped the distribution of all studies in ArcMap 10.5 (ESRI, Redlands, USA) and assessed the alignment between central species and primary livestock depredator.

\section{Results}

Our literature review returned 119 peer-reviewed publications on livestock depredation in sub-Saharan Africa published during 1997-2019. We eliminated 19 studies that did not fit the conditions of our review (e.g. did not directly examine livestock depredation or were not published in a peer-reviewed journal), so our final database comprised a total of 100 studies (Fig. 1, Supplementary Material 1). The majority of these were conducted in Eastern Africa (i.e. Ethiopia, Tanzania, Kenya; $\mathrm{n}=51$ ), and Southern Africa (i.e. Botswana, Namibia, South Africa, Zimbabwe; $n=43$ ). Six were based in Western and Central Africa (i.e. Niger, Guinea, Chad, Cameroon, Benin). Seven studies did not have any central species, as identified via lexical analysis and confirmed through the document analysis. Among those with a single central species, the African lion was the most common $(\mathrm{n}=29$; Figs $2 \& 3)$. Other single central species included the spotted hyaena (9), African wild dog (9), cheetah (7), leopard (6), black-backed jackal (5), Ethiopian wolf (4) and brown hyaena (1). The studies with at least two central species included African lions/spotted hyaenas $(n=10)$, African lions/leopards (3), African lions/spotted hyaenas/ leopards (3), and spotted hyaenas/leopards (2). There was one study each that included Ethiopian wolves/African wolves, cheetahs/black-backed jackals, black-backed jackals/caracals, spotted hyaenas/leopards/black-backed jackals, and leopards/black-backed jackals/caracals (Fig. 2).

There were 41 studies that included measures of livestock depredation. Over three-quarters $(85.4 \%, n=35)$ of these studies reported depredation events and the remainder $(14.6 \%, n=6)$ reported perceptions of depredation risk. Spotted hyaenas were the primary livestock depredator in the majority of these studies $(58.5 \%, n=18$ and $n=4$ for depredation events and perceptions of depredation risk, respectively), followed by African lions (24.4\%, $\mathrm{n}=9$ and $\mathrm{n}=2)$, leopards $(7.3 \%, \mathrm{n}=3$ and $\mathrm{n}=0)$, black-backed jackals $(4.9 \%, \mathrm{n}=2$ and $\mathrm{n}=0)$, African wild dogs $(2.4 \%, \mathrm{n}=1$ and $\mathrm{n}=0$ ), and African wolves ( $2.4 \%, \mathrm{n}=1$ and $\mathrm{n}=0$; Figs $2 \& 3$ ). Notably, not all reported measures of livestock depredation were indicative of the magnitude of loss resulting from the depredation (e.g. monetary value of the livestock killed).

Among the four most common single central species reported to depredate livestock in the reviewed studies (African lions, spotted hyaenas, African wild dogs, and leopards), there was a mismatch between central species and primary depredator for spotted hyaenas and leopards (Table 1). Spotted hyaenas were not a central species in $37.5 \%$ of the studies ( 9 of 24 ) in which they were the primary livestock depredator. We detected such a mismatch for leopards in one study (Table 1).

\section{Discussion}

Applied conservation research is most effective when research findings and conservation outputs are aligned (Balmford et al., 2003; Stroud et al., 2014; Eklund et al., 2017). A discrepancy between these two factors may limit 

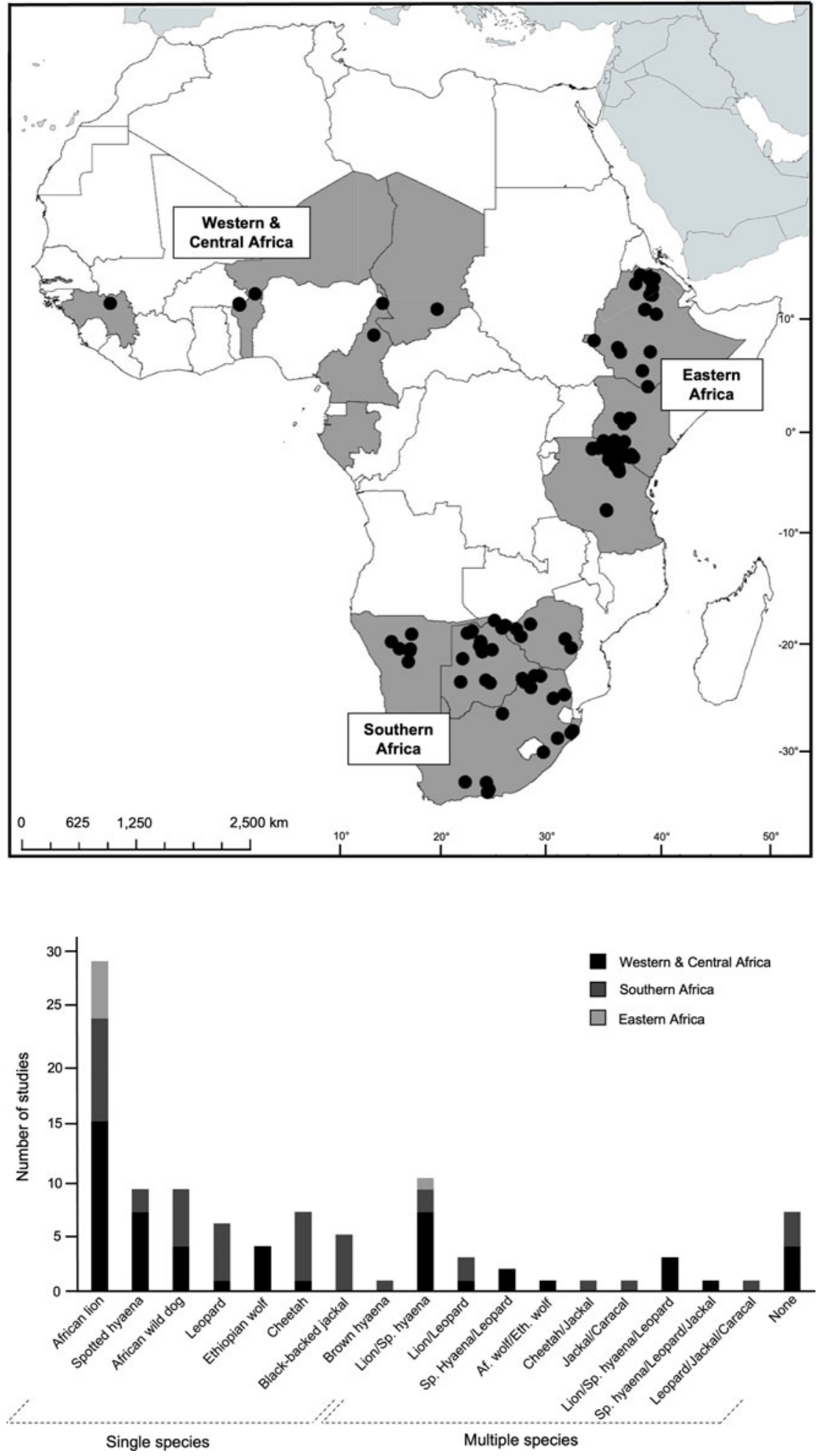

FIG. 1 The location of field sites featured in 100 studies of livestock depredation in sub-Saharan Africa published during 1997-2019.
FIg. 2 The central carnivore species among 100 studies on livestock depredation in sub-Saharan Africa (Fig. 1), indicating the number of studies with a single central species, and those with two or more central species, in Western and Central Africa, Southern Africa and Eastern Africa. the applicability of research findings for policy and management practices (Balmford et al., 2003; Linklater, 2003; Eklund et al., 2017; Gray et al., 2019). We detected a misalignment of this type within research on livestock depredation by carnivores in sub-Saharan Africa. Specifically, we found that spotted hyaenas were the central species in only a small proportion of studies despite being the most common primary livestock depredator. Similarly, in over one-third of the studies that reported spotted hyaenas as the primary livestock depredator, they were not a central species in that same study. In contrast, none of the other most common single central species reported to depredate 


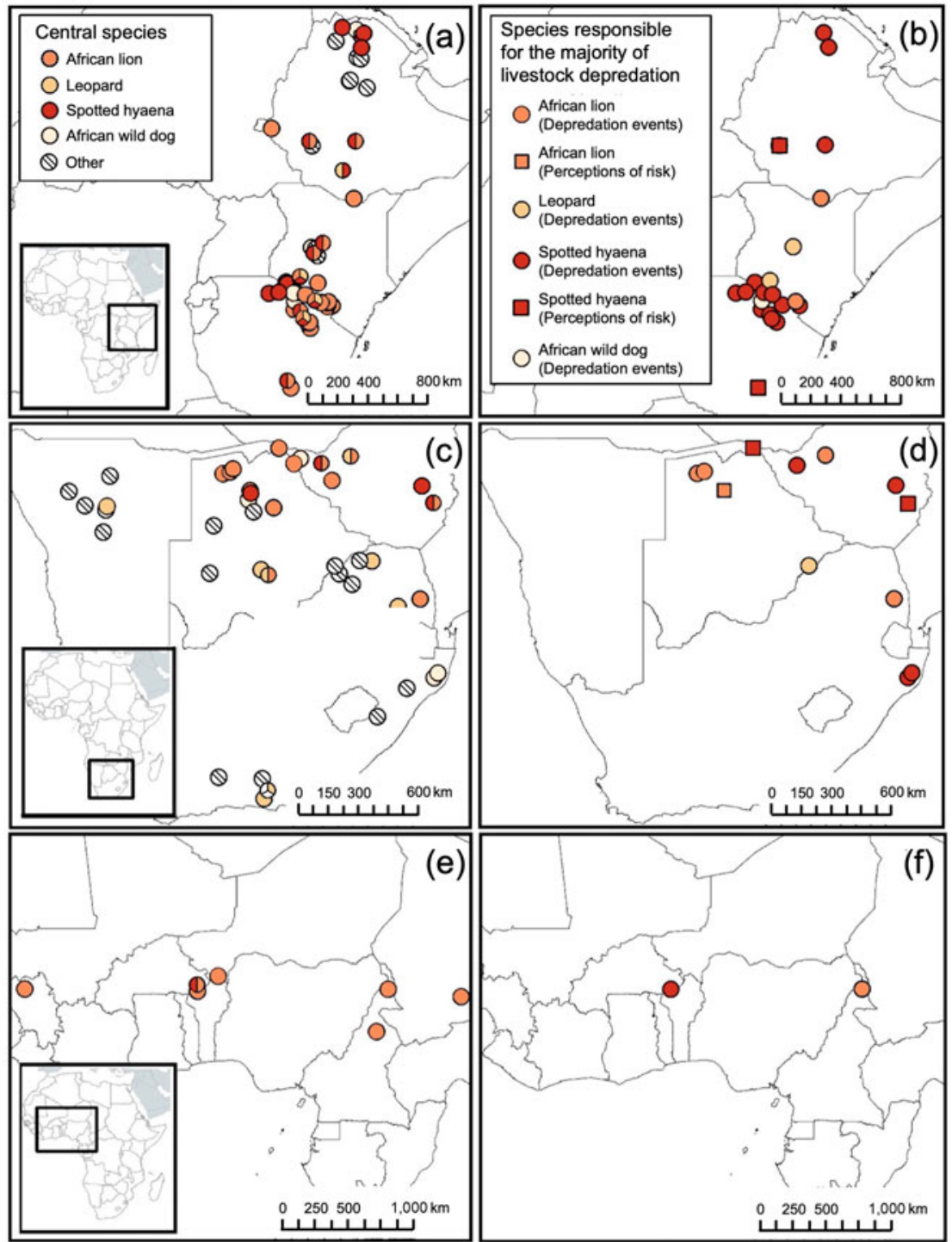

FIG. 3 The misalignment between central species (left-hand panels) and species responsible for the majority of livestock depredation (right-hand panels) for the four most common single central species reported to depredate livestock in the reviewed studies: African lion Panthera leo, leopard Panthera pardus, spotted hyaena Crocuta crocuta and African wild dog Lycaon pictus, by geographical region:
(a) and (b) Eastern Africa, (c) and
(d) Southern Africa, (e) and (f) Western and Central Africa.

TABLE 1 The alignment between central carnivore species and primary livestock depredator for 41 studies in sub-Saharan Africa published during 1997-2019, showing the number of studies in which the carnivore species responsible for the majority of livestock depredation was the only central species (single), one of multiple central species (multiple) or not a central species (mismatch) in the same study.

\begin{tabular}{|c|c|c|c|}
\hline & Single & Multiple & Mismatch \\
\hline African lion Panthera leo & 7 & 3 & 0 \\
\hline Spotted hyaena Crocuta crocuta & 4 & 11 & 9 \\
\hline Wild dog Lycaon pictus & 1 & 0 & 0 \\
\hline Ethiopian wolf Canis simensis & 0 & 0 & 0 \\
\hline Cheetah Acinonyx jubatus & 0 & 0 & 0 \\
\hline African leopard Panthera pardus & 0 & 2 & 1 \\
\hline Black-backed jackal Canis mesomelas & 0 & 1 & 1 \\
\hline Brown hyaena Parahyaena brunnea & 0 & 0 & 0 \\
\hline African wolf Canis lupaster & 0 & 1 & 0 \\
\hline Caracal Caracal caracal & 0 & 0 & 0 \\
\hline
\end{tabular}

livestock in the reviewed studies (African lion, African wild dog, leopard) showed similar rates of mismatch (Table 1). All three were more commonly central species than the primary livestock depredator. African lions, in particular, were disproportionately listed as the central species relative to their contributions as livestock depredators. They were central species in $45 \%$ of the studies but recorded as the primary livestock depredator in only $24 \%$ of the studies. These misalignments emerged in both the lexical and document analyses. These patterns are probably attributable, at least in part, to differing levels of charisma among large carnivores.

Species charisma is a relational trait, derived not from the inherent attributes of a species, but from the ways in which people respond to those attributes (Lorimer, 2007; Albert et al., 2018). Consequently, charisma is subjective and must be interpreted within the context of culture, experiences and values (Smith et al., 2012; Ducarme et al., 2013; Albert et al., 2018). Charisma is often used to refer to a 
species' ability to rally financial support for conservation (Courchamp et al., 2006; Lorimer, 2007; Macdonald et al., 2015; Albert et al., 2018). As the majority of conservation funding comes from Western societies (Albert et al., 2018), charisma is most often framed in a Western context (Ducarme et al., 2013; Courchamp et al., 2018). Within this Western perspective, African lions and leopards are consistently highly ranked in lists of the most charismatic species (Smith et al., 2012; Macdonald et al., 2015; Albert et al., 2018; Davies et al., 2018). African wild dogs are also considered to be charismatic, but their overall cultural appeal is probably reduced because they are comparatively less recognizable outside their range countries (Di Minin et al., 2013; Monsarrat \& Kerley, 2018). Spotted hyaenas, in contrast, tend to be perceived negatively nearly everywhere (Dickman, 2010; Macdonald et al., 2015). There are notable examples of local reverence, respect and tolerance for the species (Baynes-Rock, 2013). However, spotted hyaenas are commonly perceived in Western cultures as ugly, greedy, unintelligent scavengers and are almost exclusively absent from the scientific literature on charisma (Goldman et al., 2010; De Pinho et al., 2014; Mitchell et al., 2019). We infer that these narratives, and comparative lack of charisma, limit the ability of spotted hyaenas to draw financial support from Western institutions for sustained research-informed conservation.

Species such as the African lion, considered to be charismatic in the West (Albert et al., 2018), also tend to be associated with complex social dynamics in their range countries (Inskip \& Zimmermann, 2009; Dickman, 2010; Goldman et al., 2013). These dynamics may be driven by factors such as the role of the species in traditional ceremonies, the relative socio-economic position of the local communities, or the political history of the region (Inskip \& Zimmermann, 2009; Dickman, 2010; Pooley et al., 2017). The cultural implications of these factors influence the willingness of local people to participate in conservation actions (Pooley et al., 2017; van Eeden et al., 2018a,b). The social context surrounding depredating carnivores is also linked to the species' life history. The African lion, for instance, tends to select cattle over concurrently available smaller livestock such as sheep and goats (Holmern et al., 2007; Kissui, 2008; Hemson et al., 2009). As in many communities cattle carry higher economic and cultural value than other livestock types, preventing depredation by African lions is of particular importance in many parts of sub-Saharan Africa (Holmern et al., 2007; Hemson et al., 2009). Combined with high levels of charisma, this cultural context has probably resulted in species such as the African lion being prioritized as central species in human-carnivore conflict research, with less charismatic species, such as the spotted hyaena, under-emphasized. Not all reported measures of livestock depredation in the studies we reviewed were indicative of the financial or emotional impact of livestock loss, and therefore we do not contend that the African lion's prevalence in the literature is without merit. Nevertheless, we did find that taxonomic bias exists within the human-carnivore conflict literature.

This taxonomic bias has two primary consequences for the mitigation of livestock depredation, and therefore for the conservation of large carnivores in sub-Saharan Africa. Firstly, coexistence between people and large carnivores largely depends upon increasing the tolerance of local people for carnivores (Bruskotter \& Wilson, 2014; Treves \& Bruskotter, 2014; Pooley et al., 2017). Tolerance is informed by a complex combination of attitudes, behaviours and perceptions, all of which are informed by socio-cultural norms as well as political and economic trends (Goldman et al., 2013; Bruskotter \& Wilson, 2014; Treves \& Bruskotter, 2014; Margulies \& Karanth, 2018; van Eeden et al., 2018a,b). Importantly, tolerance of large carnivores is also strongly influenced by overall rates of livestock depredation (Kolowski \& Holekamp, 2006; Bruskotter \& Wilson, 2014; Treves \& Bruskotter, 2014). Increased rates of livestock depredation can degrade human attitudes towards carnivores and increase the probability of retaliatory killing, even for unoffending species or individuals (Romañach et al., 2007; Miller et al., 2016a,b; Farhadinia et al., 2017). Spotted hyaenas, as the primary depredators of livestock across much of sub-Saharan Africa, may be eroding human tolerance of sympatric carnivore species. Yet, few studies emphasize livestock depredation by this species.

The second consequence of this bias is the restriction of the knowledge base upon which conservation efforts are built. Taxonomic biases result in a large amount of knowledge on a small number of species, limiting the development of broad theoretical insights (Clark \& May, 2002; Hortal et al., 2015; Rosenthal et al., 2017). This is not to suggest that research centred on one carnivore species necessarily omits others during fundraising, data collection and analysis. It is possible that the studies we reviewed had comprehensive research-informed conservation programmes that equitably assessed depredation patterns of multiple carnivore species. However, our findings suggest that the resultant publications framed the issue of human-carnivore conflict around a small group of highly charismatic species. As one-third of the studies that identified spotted hyaenas as the primary depredator of livestock did not include them as a central species, it follows that conflict management recommendations derived from these studies are not emphasizing the impact of this species. Additionally, we suspect that conflict management recommendations as a whole are being framed around an understanding of livestock depredation by charismatic species, with recommendations for interventions derived from knowledge of the behavioural patterns of these species. The limited research on livestock depredation by spotted hyaenas indicates they exhibit patterns of depredation different from those of African lions and leopards 
(Ogada et al., 2003; Woodroffe et al., 2007; Kissui, 2008). Therefore, interventions built upon understandings of charismatic species may omit behaviours of more common depredators and consequently be limited in their ability to prevent livestock depredation.

The taxonomic bias that we detected in research on livestock depredation by carnivores in sub-Saharan Africa is consistent with other patterns observed in the conservation literature (Clark \& May, 2002; Lawler et al., 2006; Troudet et al., 2017; Tensen, 2018; Lozano et al., 2019). Conservation research tends to be biased towards vertebrates, with mammals and birds receiving a level of research effort disproportionate to their prevalence in nature and, in many cases, to their level of extinction risk (Clark \& May, 2002; Donaldson et al., 2017; Davies et al., 2018). These types of biases correlate with species charisma, resulting in the majority of research focusing on taxa that contain colourful, large, distinctive species (Bonnet et al., 2002; Clark \& May, 2002; Lawler et al., 2006; Donaldson et al., 2017). For example, Brambilla et al. (2013) found that more appealing bird species in Italy received significantly more research attention, and Fleming \& Bateman (2016) reported that unattractive Australian mammals were underrepresented in the literature. The consequences of such biases have been examined in the fields of climate change mitigation (Feeley et al., 2017), animal behaviour (Rosenthal et al., 2017), species reintroductions (Seddon et al., 2005) and conservation more broadly (Clark \& May, 2002; Lawler et al., 2006; Stroud et al., 2014; Di Marco et al., 2017). There is clear evidence that these biases limit the development of ecological theory and conservation management practices (Lawler et al., 2006; Fleming \& Bateman, 2016). Thus, taxonomic bias is a potential driver of the research-implementation gap in conservation (Seddon et al., 2005; Amori et al., 2008; Martín-López et al., 2009; Troudet et al., 2017).

Another important component of taxonomic bias relates to conservation funding, which tends to disproportionately support charismatic species (Stroud et al., 2014; Fleming \& Bateman, 2016; Di Marco et al., 2017; Davies et al., 2018; Curtin \& Papworth, 2020). Many of the largest conservation NGOs explicitly focus their funding efforts on charismatic species (Brockington \& Scholfield, 2010a,b; Holmes et al., 2012). Prioritization of funding in conservation is determined by both political agendas and social contexts (Martín-López et al., 2009; Stroud et al., 2014). Public interest in charismatic species motivates donations, which support further opportunities to study those same species (Davies et al., 2018). Furthermore, as reviewers and researchers are implicitly biased towards articles that emphasize their own study organisms, the literature continues to highlight the same subset of charismatic species (Bonnet et al., 2002; Wilson et al., 2007; Martín-López et al., 2009; Rosenthal et al., 2017). This bias is evident in carnivore conservation, with large felids consistently receiving more funding and research effort than other species (Davies et al., 2018; Curtin \& Papworth, 2020), which is particularly notable in Africa (Di Marco et al., 2017). For example, in 2017 the Leonardo DiCaprio Foundation announced a USD 1 million seed donation to establish the Lion Recovery Fund in collaboration with the Wildlife Conservation Network. This effort was subsequently supported by a variety of additional sponsors, including the Disney Conservation Fund. Within its first year, the fund distributed c. USD 2.4 million across 28 research and conservation projects centred on the African lion (Lion Recovery Fund Progress Report, 2018). Similarly, National Geographic's Big Cat Initiative had an open request for proposals, up to mid 2021, for research programmes examining lion conservation in 20 lionspecific priority areas. Through this initiative, up to USD 100,000 of support was awarded per project. These conservation funds are allocated across a geographical range where less charismatic spotted hyaenas co-occur and tend to be more problematic for livestock owners than African lions.

It is possible that the negative effects of taxonomic bias could be ameliorated by the flagship species concept, with conservation of co-occurring species aided by the focus of conservation attention on large, charismatic species (Andelman \& Fagan, 2000; Roberge \& Angelstam, 2004; Smith et al., 2012; Albert et al., 2018). Flagship species tend to be large-bodied mammals that are often described as beautiful or impressive (Albert et al., 2018). Conservation status can also contribute to species charisma (Martín-López et al., 2009; Albert et al., 2018). Species at greater risk of extinction, particularly those that are charismatic, tend to motivate conservation engagement and fundraising (Courchamp et al., 2006; Smith et al., 2012; Brambilla et al., 2013; Albert et al., 2018). The spotted hyaena is categorized as Least Concern on the IUCN Red List and thus carries little power for motivating conservation engagement from the perspective of species rarity. However, the African lion and leopard are categorized as Vulnerable and the African wild dog as Endangered. As the populations of these three species continue to decline, their value as conservation flagships grows (Martín-López et al., 2009; Ripple et al., 2014; Wolf \& Ripple, 2017). However, the extent to which the flagship species concept demonstrably supports the conservation of species other than the flagship is a source of debate (Andelman \& Fagan, 2000; Caro et al., 2004).

Recent studies have indicated the benefits of strategic prioritization of charismatic species to further broad-scale biodiversity conservation (Smith et al., 2012; Bennett et al., 2015; McGowan et al., 2020). However, such an approach may have adverse effects on the development of practices intended to address human-carnivore conflict. We recognize that as our study focuses on large carnivores in sub-Saharan Africa, it could be considered to have its own bias. Nevertheless, we believe our critical assessment contributes 
to the literature on human-carnivore interactions by helping to improve the conservation impact of future research in this field. Our findings indicate that current patterns of research prioritization are resulting in a misalignment between the drivers of human-carnivore conflict and research on that topic. Consequently, conflict intervention practices founded upon that research may be limited in their ability to mitigate declines in large carnivore populations. Solutions for this global conservation challenge may be better served by alternate prioritization schemes that promote species-specific knowledge and more comprehensive understanding of the patterns of livestock depredation. We advocate increased incentivization of the study of livestock depredation by less charismatic carnivore species, including the spotted hyaena. This will facilitate the explicit examination of the effectiveness of conflict mitigation efforts.

The call for research on less charismatic species is often based upon the conservation status of those species, where their relative omission from the literature may be increasing their risk of extinction (Seddon et al., 2005; Brambilla et al., 2013). Here, we provide evidence for an additional motive for addressing this bias, as the underrepresentation of spotted hyaenas is unlikely to put the species itself at risk of extinction. Instead, we show that in the case of livestock depredation, and subsequent human-carnivore conflict, this bias may be negatively impacting the conservation of other depredating species as well. As taxonomic bias is widespread in conservation, further examination is likely to reveal similar trends in other regions and fields of study. Our study suggests that increased examination of current patterns of funding and research effort is needed to bridge the existing gap between conservation priorities and conservation research.

Acknowledgements We thank J.M. Beck for insightful comments. CFH is supported by the University Fellowship Program at Michigan State University, but this research received no specific grant from any funding agency, or commercial or not-for-profit sectors.

Author contributions Analysis, writing: all authors.

\section{Conflicts of interest None.}

Ethical standards This research abided by the Oryx guidelines on ethical standards.

\section{References}

Albert, C., Luque, G.M. \& Courchamp, F. (2018) The twenty most charismatic species. PLOS ONE, 13, eo199149.

Amori, G., Gippoliti, S. \& Helgen, K.M. (2008) Diversity, distribution, and conservation of endemic island rodents. Quaternary International, 182, 6-15.

Andelman, S.J. \& FaGAN, W.F. (2000) Umbrellas and flagships: efficient conservation surrogates or expensive mistakes? Proceedings of the National Academy of Sciences of the United States of America, 97, 5954-5959.

Anon. (2007) The great divide. Nature, 450, 135-136.

Balmford, A., Gaston, K.J., Blyth, S., James, A. \& Kapos, V. (2003) Global variation in terrestrial conservation costs, conservation benefits, and unmet conservation needs. Proceedings of the National Academy of Sciences of the United States of America, 100, 1046-1050.

BAynes-Rock, M. (2013) Local tolerance of hyena attacks in East Hararge Region, Ethiopia. Anthrozoös, 26, 421-433.

Bednarek, M. \& Caple, H. (2014) Why do news values matter? Towards a new methodological framework for analysing news discourse in critical discourse analysis and beyond. Discourse \& Society, 25, 135-158.

Bennett, J.R., Maloney, R. \& Possingham, H.P. (2015) Biodiversity gains from efficient use of private sponsorship for flagship species conservation. Proceedings of the Royal Society B, 282, 20142693.

Bonnet, X., Shine, R. \& Lourdais, O. (2002) Taxonomic chauvinism. Trends in Ecology \& Evolution, 17, 1-3.

Brambilla, M., Gustin, M. \& Celada, C. (2013) Species appeal predicts conservation status. Biological Conservation, 160, 209-213.

Brockington, D. \& Scholfield, K. (2010a) The conservationist mode of production and conservation NGOs in sub-Saharan Africa. Antipode, 42, 551-575.

Brockington, D. \& Scholfield, K. (2010b) Expenditure by conservation nongovernmental organizations in sub-Saharan Africa. Conservation Letters, 3, 106-113.

Bruskotter, J.T. \& Wilson, R.S. (2014) Determining where the wild things will be: using psychological theory to find tolerance for large carnivores. Conservation Letters, 7, 158-165.

Caro, T., Engilis, A., Fitzherbert, E. \& Gardner, T. (2004) Preliminary assessment of the flagship species concept at a small scale. Animal Conservation, 7, 63-70.

Chapron, G., Kaczensky, P., Linnell, J.D.C., von Arx, M., Huber, D., ANDRÉn, H. et al. (2014) Recovery of large carnivores in Europe's modern human-dominated landscapes. Science, 346, 1517-1519.

Clark, J.A. \& MAY, R.A. (2002) Taxonomic bias in conservation research. Science, 297, 191-192.

Courchamp, F., Angulo, E., Rivalan, P., Hall, R.J., Signoret, L., Bull, L. \& Meinard, Y. (2006) Rarity value and species extinction: the anthropogenic Allee effect. PLOS Biology, 4, 2405-2410.

Courchamp, F., Jaric, I., Albert, C., Meinard, Y., Ripple, W.J. \& Chapron, G. (2018) The paradoxical extinction of the most charismatic animals. PLOS Biology, 16, e2003997.

Curtin, P. \& Papworth, S. (2020) Coloring and size influence preferences for imaginary animals, and can predict actual donations to species-specific conservation charities. Conservation Letters, 13 , e12723.

Davies, T., Cowley, A., Bennie, J., Leyshon, C., Inger, R., Carter, H. et al. (2018) Popular interest in vertebrates does not reflect extinction risk and is associated with bias in conservation investment. PLOS ONE, 13, eо203694.

De Pinho, J.R., Grilo, C., Boone, R.B., Galvin, K.A. \& Snodgrass, J.G. (2014) Influence of aesthetic appreciation of wildlife species on attitudes towards their conservation in Kenyan Agropastoralist communities. PLOS ONE, 9, 88842.

Di Marco, M., Chapman, S., Althor, G., Kearney, S. \& Watson, J.E.M. (2017) Changing trends and persisting biases in three decades of conservation science. Global Ecology and Conservation, $10,32-42$.

Di Minin, E., Fraser, I., Slotow, R. \& MacMillan, D.C. (2013) Understanding heterogeneous preference of tourists for big game species: implications for conservation and management. Animal Conservation, 16, 249-258. 
Dickman, A.J. (2010) Complexities of conflict: the importance of considering social factors for effectively resolving human-wildlife conflict. Animal Conservation, 13, 458-466.

Donaldson, M.R., Burnett, N.J., Braun, D.C., Suski, C.D., Hinch, S.G., Cooke, S.J. \& KerR, J.T. (2017) Taxonomic bias and international biodiversity conservation research.

Facets, 1, 105-113.

dos Santos, J.W., Correia, R.A., Malhado, A.C.M., CamposSilva, J.V., Teles, D., Jepson, P. \& Ladle, R.J. (2020) Drivers of taxonomic bias in conservation research: a global analysis of terrestrial mammals. Animal Conservation, 23, 679-688.

Ducarme, F., Luque, G. \& Courchamp, F. (2013) What are 'charismatic species' for conservation biologists? BioSciences Master Reviews, 1-8.

Eklund, A., López-Bao, J.V., Tourani, M., Chapron, G. \& Frank, J. (2017) Limited evidence on the effectiveness of interventions to reduce livestock predation by large carnivores. Scientific Reports, 7, 2097.

Estes, J.A., Terborgh, J., Brashares, J.S., Power, M.E., Berger, J., Bond, W.J. et al. (2011) Trophic downgrading of planet Earth. Science, 333, 301-306.

Farhadinia, M.S., Johnson, P.J., Hunter, L.T.B. \& Macdonald, D.W. (2017) Wolves can suppress goodwill for leopards: patterns of human-predator coexistence in northeastern Iran. Biological Conservation, 213, 210-217.

Fazey, I., Fischer, J. \& Lindenmayer, D.B. (2005) What do conservation biologists publish? Biological Conservation, 124, 63-73.

Feeley, K.J., Stroud, J.T. \& Perez, T.M. (2017) Most 'global' reviews of species' responses to climate change are not truly global. Diversity and Distributions, 23, 231-234.

Fleming, P.A. \& Bateman, P.W. (2016) The good, the bad, and the ugly: which Australian terrestrial mammal species attract most research? Mammal Review, 46, 241-254.

Goldman, M.J., De Pinho, J.R. \& Perry, J. (2010) Maintaining complex relations with large cats: Maasai and lions in Kenya and Tanzania. Human Dimensions of Wildlife, 15, 332-346.

Goldman, M.J., De Pinho, J.R. \& Perry, J. (2013) Beyond ritual and economics: Maasai lion hunting and conservation politics. Oryx, 47, 490-500.

Gray, S.M., Booher, C.R., Elliott, K.C., Kramer, D.B., Waller, J.C., Millspaugh, J.J. et al. (2019) Research-implementation gap limits the actionability of human-carnivore conflict studies in East Africa. Animal Conservation, 23, 7-17.

Hemson, G., Maclennan, S., Mills, G., Johnson, P. \& Macdonald, D. (2009) Community, lions, livestock and money: a spatial and social analysis of attitudes to wildlife and the conservation value of tourism in a human-carnivore conflict in Botswana. Biological Conservation, 142, 2718-2725.

Holmern, T., Nyahongo, J. \& Røskaft, E. (2007) Livestock loss caused by predators outside the Serengeti National Park, Tanzania. Biological Conservation, 135, 518-526.

Holmes, G., Scholfield, K. \& Brockington, D. (2012) A comparison of global conservation prioritization models with spatial spending patterns of conservation nongovernmental organizations. Conservation Biology, 26, 602-609.

Hortal, J., De Bello, F., Diniz-Filho, J.A.F., Lewinsohn, T.M., LoBo, J.M. \& LADLE, R.J. (2015) Seven shortfalls that beset large-scale knowledge of biodiversity. Annual Review of Ecology, Evolution, and Systematics, 46, 523-549.

Inskip, C. \& ZimmermanN, A. (2009) Human-felid conflict: a review of patterns and priorities worldwide. Oryx, 43, 18-34.

KIssuI, B.M. (2008) Livestock predation by lions, leopards, spotted hyenas, and their vulnerability to retaliatory killing in the Maasai steppe, Tanzania. Animal Conservation, 11, 422-432.
Knight, A.T., Cowling, R.M., Rouget, M., Balmford, A., Lombard, A.T. \& CAmpbell, B.M. (2008) Knowing but not doing: selecting priority conservation areas and the researchimplementation gap. Conservation Biology, 22, 610-617.

Kolowski, J.M. \& Holekamp, K.E. (2006) Spatial, temporal, and physical characteristics of livestock depredations by large carnivores along a Kenyan reserve border. Biological Conservation, 128, 529-541.

Krafte Holland, K., Larson, L.R. \& Powell, R.B. (2018) Characterizing conflict between humans and big cats Panthera spp: a systematic review of research trends and management opportunities. PLOS ONE, 13, e0203877.

Kuckartz, U. \& Radiker, S. (2019) Analyzing Qualitative Data with MAXQDA: Text, Audio, and Video. Springer Nature Switzerland, Cham, Switzerland.

Lawler, J.J., Aukema, J.E., Grant, J.B., Halpern, B.S., Kareiva, P., Nelson, C.R. et al. (2006) Conservation science: a 20-year report card. Frontiers in Ecology and the Environment, 4, 473-48o.

LinkLATER, W.L. (2003) Science and management in a conservation crisis: a case study with Rhinoceros. Conservation Biology, 17, 968-975.

Lion Recovery Fund (2018) Progress Report. s27142.pcdn.co/wpcontent/uploads/2018/o8/LRF-2018-Progress-Report.pdf [accessed 12 November 2021].

Lorimer, J. (2007) Nonhuman charisma. Environment and Planning D: Society and Space, 25, 911-932.

Lozano, J., Olszańska, A., Morales-Reyes, Z., Castro, A.A., Malo, A.F., Moleón, M. et al. (2019) Human-carnivore relations: a systematic review. Biological Conservation, 237, 480-492.

Macdonald, E.A., Burnham, D., Hinks, A.E., Dickman, A.J., Malhi, Y. \& Macdonald, D.W. (2015) Conservation inequality and the charismatic cat: Felis felicis. Global Ecology and Conservation, 3, 851-866.

Margulies, J.D. \& Karanth, K.K. (2018) The production of human-wildlife conflict: a political animal geography of encounter. Geoforum, 95, 153-164.

Marker, L., Mills, M. \& Macdonald, D. (2003) Factors influencing perceptions of conflict and tolerance toward cheetahs on Namibian farmlands. Conservation Biology, 17, 1290-1298.

Martín-López, B., Montes, C., Ramírez, L. \& Benayas, J. (2009) What drives policy decision-making related to species conservation? Biological Conservation, 142, 1370-1380.

McGowan, J., Beaumont, L.J., Smith, R.J., Chauvenet, A.L.M., Harcourt, R., Atrinson, S.C. et al. (2020) Conservation prioritization can resolve the flagship species conundrum. Nature Communications, 11, 994.

Miller, J.R.B., Jhala, Y.V. \& Jena, J. (2016a) Livestock losses and hotspots of attack from tigers and leopards in Kanha Tiger Reserve, Central India. Regional Environmental Change, 16, 17-29.

Miller, J.R.B., Jhala, Y.V. \& Schmitz, O.J. (2016b) Human perceptions mirror realities of carnivore attack risk for livestock: implications for mitigating human-carnivore conflict. PLOS ONE, 11, e0162685.

Mitchell, A.M., Bruyere, B.L., Otieno, T.O., Bhalla, S. \& Teel, T.L. (2019) A comparison between human-carnivore conflicts and local community attitudes toward carnivores in Westgate Community Conservancy, Samburu, Kenya. Human Dimensions of Wildlife, 24, 168-179.

Monsarrat, S. \& Kerley, G.I.H. (2018) Charismatic species of the past: biases in reporting of large mammals in historical written sources. Biological Conservation, 223, 68-75.

Montgomery, R.A., Elliot, K.C., Hayward, M.W., Gray, S.M., Millspaugh, J.J., Riley, S.J. et al. (2018a) Examining evident interdisciplinarity among prides of lion researchers. Frontiers in Ecology and Evolution, 6, 49. 
Montgomery, R.A., Hoffmann, C.F., Tans, E.D. \& Kissui, B. (2018b) Discordant scales and the potential pitfalls for humancarnivore conflict mitigation. Biological Conservation, 224, 170-177.

Ogada, M.O., Woodroffe, R., Oguge, N.O. \& Frank, L.G. (2003) Limiting depredation by African carnivores: the role of livestock husbandry. Conservation Biology, 17, 1521-1530.

Pooley, S., Barua, M., Beinart, W., Dickman, A., Holmes, G., Lorimer, J. et al. (2017) An interdisciplinary review of current and future approaches to improving human-predator relations. Conservation Biology, 31, 513-523.

Redpath, S.M. (2015) Tilting at wildlife: reconsidering humanwildlife conflict. Oryx, 49, 222-225.

Redpath, S.M., Young, J., Evely, A., Adams, W.M., Sutherland, W.J., Whitehouse, A. et al. (2013) Understanding and managing conservation conflicts. Trends in Ecology \& Evolution, 28, 100-109.

Ripple, W.J., Chapron, G., López-Bao, J.V., Durant, S.M., Macdonald, D.W., Lindsey, P.A. et al. (2016) Saving the world's terrestrial megafauna. BioScience, 66, 807-812.

Ripple, W.J., Estes, J.A., Beschta, R.L., Wilmers, C.C., Ritchie, E.G., Hebblewhite, M. et al. (2014) Status and ecological effects of the world's largest carnivores. Science, 343, 151-162.

Roberge, J.M. \& Angelstam, P. (2004) Usefulness of the umbrella species concept as a conservation tool. Conservation Biology, $18,76-85$.

Romañach, S.S., Lindsey, P.A. \& Woodroffe, R. (2007) Determinants of attitudes towards predators in central Kenya and suggestions for increasing tolerance in livestock dominated landscapes. Oryx, 41, 185-195.

Rosenthal, M.F., Gertler, M., Hamilton, A.D., Prasad, S. \& Andrade, C.B. (2017) Taxonomic bias in animal behaviour publications. Animal Behaviour, 127, 83-89.

Seddon, P.J., Soorae, P.S. \& Launay, F. (2005) Taxonomic bias in reintroduction projects. Animal Conservation, 8, 51-58.

Smith, R.J., Veríssimo, D., Isaac, N.J.B. \& Jones, K.E. (2012) Identifying Cinderella species: uncovering mammals with conservation flagship appeal. Conservation Letters, 5, 205-212.

Stroud, J.T., Rehm, E., Ladd, M., Olivas, P. \& Feeley, K.J. (2014) Is conservation research money being spent wisely? Changing trends in conservation research priorities. Journal for Nature Conservation, 22, 471-473.

Tensen, L. (2018) Biases in wildlife and conservation research, using felids and canids as a case study. Global Ecology and Conservation, 15, eoo423.

Treves, A. \& Bruskotter, J. (2014) Tolerance for predatory wildlife. Science, 344, 476-477.

Trimble, M.J. \& van Aarde, R.J. (2012) Geographical and taxonomic biases in research on biodiversity in human-modified landscapes. Ecosphere, 3, 119.

Troudet, J., Grandcolas, P., Blin, A., Vignes-Lebbe, R. \& Legendre, F. (2017) Taxonomic bias in biodiversity data and societal preferences. Nature Scientific Reports, 7, 9132.

Tumenta, P., de Iongh, H., Funston, P.J. \& Udo de Haes, H.A. (2013) Livestock depredation and mitigation methods practised by resident and nomadic pastoralists around Waza National Park, Cameroon. Oryx, 47, 237-242.

van Eeden, L.M., Crowther, M.S., Dickman, C.R., Macdonald, D.W., Ripple, W.J., Ritchie, E.G. \& Newsome, T.M. (2018a) Managing conflict between large carnivores and livestock. Conservation Biology, 32, 26-34.

van Eeden, L.M., Eklund, A., Miller, J.R.B., López-Bao, V., Chapron, G., Cejtin, M.R. et al. (2018b) Carnivore conservation needs evidence-based livestock protection. PLOS Biology, 16, e2005577.

Wilson, J.R.U., Proches, S., Braschler, B., Dixon, E. \& Richardson, D.M. (2007) The (bio) diversity of society of science reflects the interests The Ecological Society America. Frontiers in Ecology and the Environment, 5, 409-414.

WodAk, R. \& MEYer, M. (2008) Critical discourse analysis: history, agenda, theory, and methodology. In Methods of Critical Discourse Analysis (eds R. Wodak \& M. Meyer), pp. 1-34, 2nd edition. SAGE Publications, Los Angeles, USA.

Wolf, C. \& Ripple, W.J. (2017) Range contractions of the world's large carnivores. Royal Society Open Science, 4, 170052.

Woodroffe, R., Frank, L.G., Lindsey, P.A., ole Ranah, S.M.K. \& RomañaCH, S. (2007) Livestock husbandry as a tool for carnivore conservation in Africa's community rangelands: a case-control study. Biodiversity and Conservation, 16, 1245-1260. 